\title{
ENKELE GREPE UIT DIE OU-TESTAMENTIESE WETENSKAP IN DIE AFGELOPE VYFTIG JAAR
}

\author{
deur
}

\author{
Prof. E. S. MULder
}

Waar ons vanjaar die vyftigste bestaan van die Teologiese Fakulteit aan die Universiteit van Pretoria herdenk en daarmee ook die vyftigjarige bestaan van die Teologiese Opleiding van ons Kerk wil ek vandag met die aanvang van die nuwe jaarkursus $u$ aandag vra en met $u$ besin oor daardie deel van die teologiese wetenskap wat my leeropdrag is en wel oor wat soal gebeur het in die halfeeu wat nou verby is. Nou weet ek wel dat om 'n greep te doen uit 'n studieveld van eeue is 'n moeilike onderneming. Wat plaasgevind het in die vyftig jaar wat nou verby is, staan nie los van wat voorafgegaan het nie en net so min van wat in die komende halfeeu sal plaasvind op die terrein van die Ou-Testamentiese studie. Ook hier geld die spreuk

In het heden ligt 't verleden,

In het nu wat worden zal.

Dit was op 29 September 1921 op die eerste Duitse Orientalistedag in Leipzig dat Rudolf Kittel, die ons bekende van die Biblica Hebraica, 'n referaat gehou het oor "Die toekoms van die OuTestamentiese wetenskap". Hy het so begin : Menere, as ek aan $\mathrm{u}$ enige gedagtes oor die toekoms van die $\mathrm{Ou}$ Testament wetenskap moet voordra dan glo ek dat ek alleen reg daaraan kan laat geskied, as ek uitgaan van die onmiddellike verlede en daarby die teenwoordige stand van ons wetenskap.

Al sou ons die O.T. wetenskap nie op 'n bepaalde tydstip kan afgrens nie het daar tog na die end van die eerste wêreldoorlog 'n nuwe fase ingetree. Daar is nuwe weë ingeslaan en nuwe doelstellinge is vasgelê. Kittel onderskei op daardie oomblik drie stadia in die navorsingsgeskiedenis nl.:

1. Die stadium van die algemene kritiese verwerping van die oorgelewerde dogmaties-bepaalde beeld van die O.T. tot die begin van die 19de eeu.

2. Die stadium van die eerste vaste gegewens wat betref literatuur, geskiedenis en godsdiensgeskiedenis. (Wellhausen.)

3. Die in die jongste verlede opkomende stadium van 'n histor- 
riese en godsdienshistoriese nieu-orientering.

In daardie tyd d.w.s. in 1921 merk hy drie strominge op nl.:

1. Die literêr-kritiese navorsing in die styl van Wellhausen is aan die gang.

2. Die arbeid van Herman Gunkel en sy skool, die godsdienshistoriese of soos Kittel dit noem die „esteties folkloristiese" skool.

3. 'n Groep wat daarvoor ywer om die sinagogale en oud-

kerklike tradisie te bewaar en te handhaaf.

Kittel stel sy visie dan so; Wat die teologie nodig het is vooralles 'n „Geistesgeschichte" van Israel, sy geestelike lewe binne en buite die literatuur. Die werklike lewe moet eers gesoek en beluister word en daarna pas moet sy literêre neerslag verstaan en waardeer word. As doel stel hy : Die „Herausarbeitung” van die spesifiek religieuse waardes in die O.T. religie.

Toe Hugo Gressmann in 1924 hoofredakteur van die bekende Zeitschrift für alttestamentliche Wissenschaft geword het na die afsterwe van Karl Marti het hy by die aanvang 'n artikel geskrywe oor „Die Aufgabe der alttestamentlichen Forschung”. Hy skrywe: Waar die wetenskap in beweging bly, daar wissel die taak met elke navorsersgeslag, omdat daar naas die ou weë nuwes is, wat lei na dieselfde doel, en daarom kan daar moeilik van 'n „teenwoordige stand" gespreek word. Die oue is besig om verby te gaan en die nuwe om te word. Hy getuig sy instemming met die referaat van Rud. Kittel. Gressmann sien ook die verbygegane periode as dié een van die literêre kritiek. Maar, so skryf hy - Die literêr-kritiese periode mag oorwin wees maar nie die literêre kritiek nie en nie die literêr-kritiese gegewens aangaande die Hextateuch nie. Tekskritiek en literêre kritiek vorm nog die grondslag, as daar nie op lugleegtes gebou wil word nie. Gressmann sien die taak van die O.T. navorsing sesvoudig, waar voorop staan dat by die navorsing van die O.T. van die O.T. self uitgegaan moet word, as daar vaste bodem moet wees om nie verlore te raak in die Nabye Ooste nie. Die Ou Testament is ' $n$ wêreld in homself, wat homself moet verklaar. Die besonderlike van Israel moet aan die lig kom, want skryf Gressmann - Elke volk het sy indiwiduele siel.

Hierdie twee artikels van Kittel en Gressmann in die vroeë twintigerjare het 'n toekomstaak vir die O.T. wetenskap in die vooruitsig gestel en die vraag kom op in hoeverre het dit in 
vervulling gegaan? Onafgebroke het die wetenskaplike arbeid aan die O.T. voortgegaan. Die navorsing van die Bybelteks, die Hebreeuse en die Septuaginta-teks het toegeneem in intensiteit en omvang. Ook op die gebied van die filologie en die Hebreeuse grammatika is groot voortgang te boekstaaf. Die vergelykende grammatika van die Semitiese tale het die materiaal georden en het ' $n$ juiste verstaan van die Hebreeus binne die raamwerk van die oud-Oosterse tale moontlik gemaak. Die navorsing op die terrein van die Ou Testament het, soos Kittel en Gressmann die gevisualiseer het, nuwe onvermoede vergesigte geopen. Die „werklike lewe" - so Kittel - is gesoek en beluister. In hierdie soek en luister is 'n belangrike faset van die "werklike lewe" cntsluit, 'n gebied waarin die "spesifiek religieuse waardes" aldus Kittel - na vore gekom het nl. die kultus. Deur die Babiloniese bronnevondste het dit duidelik geword dat die belangrikste religieuse lewensuiting van die antieke mens, plaasgevind het in die kultus. Dit was Paul Volz wat in sy boek "Das Neujahrsfest Jahwăs" d.i. die Loofhuttefees, dit so stel By die badevaartsfeeste bereik die Israelitiese-Joodse volk die hoogtepunt van sy kultiese en nasionale lewe, net soos wat dit in Babel die geval was, wanneer die Babiloniërs om hulle hoofgod Marduk te eer na die stad van hulle godheid stroom. Hierdie feeste, so betoog Volz, het 'n sentrale en bepalende betekenis gehad in die lewe van Israel. Van al die feeste was die Nuwejaarsfees die belangwekkendste, dit was die hoogtepunt van die kultiese lewe van Israel. Hier was die „werklike lewe", hierin was vervat die "spesifiek religieuse waardes". Die ondersoek van Volz was slegs 'n voorloper. Die eintlike stoot het gekom van die Noorse Outestamentikus Sigmund Mowinckel, wat in sy magistrale werk Psalmenstudien en veral in die derde deel „Das Thronbesteigungsfest Jahwās und der Ursprung der Eschatologie" die kultiese probleme uiteenset. $\mathrm{Na}$ analogie van die Babiloniese Nuwejaarsfees neem Mowinckel ook vir Israel 'n soortgelyke fees aan. Waar in Babel Marduk as god van die skepping op die Nuwejaarsfees opnuut geîntroniseer word en as heer van die kosmiese orde geëer word, word dit in Israel op Jahwe oorgedra. Ook Jahwe bestyg dan opnuut sy troon - soos blyk uit die intronisasieroep - Jahwe het Koning geword - in die psalms $47,93,96,97,98,99$. Die grondliggende gedagte is dít, die kultus is nie net oorspronklik, maar oral en altyd 'n drama. Kultus is heilige kuns, maar is tegelyk heilige werklikheid, nie net drama wat gespeel word nie, maar 'n spel wat met reële krag die gedramatiseerde gebeurtenis verwerklik, waaruit werklike krag straal, dus 'n sakrament. By die kultus gebeur daar telkens weer 
wat daar op die môre van die tye gebeur het. Mowinckel verstaan die troonsbeklimming dan ook deurgaans presenties. Op die moment, nou, terwyl Jahwe sy troon beklim, is sy heerskappy 'n aktuele gebeure. As hy sy troon bestyg vestig hy daarmee sy ryk. Die troonsbestygingsdag is die funderingsdag van die Godsryk, die fees is 'n Godsrykfees.

Die troonsbeklimmingsfees van Jahwe, wat Mowinckel glo dat hy ontdek het, het die sleutel geword van die verklaring van die Ou Testament, èn wat die Psalms én wat die profetiese geskrifte betref. So spreek Mowinckel van kultusprofesie en kultusprofetiese psalms. So het hy ook voorloper geword van die nog onopgeloste vraag in die teenwoordige tyd van die verhouding en verband tussen kultus en profeet. Die stellings van Mowinckel het in die jare na 1922 lewendige diskussies uitgelok, het baie aanhangers en baie bestryers gevind, maar nietemin is 'n nuwe gebied van wat Kittel genoem het die "werklike lewe" van Israel daardeur blootgelê.

Die opbloei van die godsdienswetenskap het eweens veroorsaak dat die geskiedenis van die Israelities-joodse godsdiens binne die raamwerk van die algemene godsdienswetenskap getrek is. $\mathrm{Na} 1918$ merk ons 'n nuwe belangstelling in die O.T. wetenskap ook vir die besondere eie aard van Israel. Joh. Pedersen, hoogleraar in Semitiese filosofie aan die Universiteit van Kopenhagen, publiseer in 1920 sy groot werk, „Israel, its life and culture”, I, II, waarin voorop staan die begrippe „siel” en „heiligheid". Baie duidelik en helder bring Pedersen die besondere aard van die Israelitiese denke en geloof na vore. Die vraag na die werklike lewe, na die wêreld van die Ou Testament soos wat Kittel en Gressmann dit gestel het, kom te staan in die middelpunt van die O.T. navorsing. Hierdie rigting in die O.T. wetenskap vind hierna sy duidelikste uitdrukking in die werke van Albrecht Alt, waarvan tereg gesê kan word dat dit die grondslag is van die nuwere navorsing. In die twintigerjare was die vroeë geskiedenis van Israel nogal 'n lastige probleem. So was dit in ons studentejare nog 'n groot vraag hoedat die patriargfigure in Genesis verstaan moet word.

Die opvattings het wyd uiteengeloop - was hulle historiese figure, of was hulle gode of was hulle stamheroë? In 1929 verskyn die werk van Alt - „Der Gott der Văter, ein Beitrag zur Vorgeschichte der israelitischen Religion". Daarin kom Alt tot vier belangrike gevolgtrekkinge :

1. Abraham, Isak en Jakob is eg menslike persoonsname . 
2. Die drie aartsvaders is te beskou as openbaringontvangers en kultusstigters.

3. Die tradisies van die God van die vaders is na die landsbesetting verbind met die Kananitiese lokale oorleweringe.

4. Die kultus van die vadergode het die geloof van die Mosestyd voorberei.

'n Verdere probleem van die geskiedenis van Israel het opgeduik en wel die na die besetting van Kanaan. Hoe het die vestiging geskied? Dit is die groot verdienste van Alt dat my metodes ontwikkel het, waardeur die beantwoording van die vraag moontlik geword het. By sy arbeid gaan hy uit van drie bronne.

1. Die Ou Testament met sy berigte oor die vestiging in die land.

2. Die dokumente tot beskikking uit die ou wêreld, die Amarnatablette, die Palestina-lys van Thutmoses III en ander tekste.

Die vestiging in Kanaan sien Alt dan as volg: „Dit was in hoofsaak ' $n$ inbesitneem van díe dele wat voorheen grotendeels groter politieke eenhede gevorm het, veral die bergagtige dele wat nie deel gehad het aan die vorming van stadstate nie. Hierdie dele wat politiek swakker en yler bevolk was kon die indringing van die Israeliete nie afweer nie en het die beste moontlikhede gevorm vir die vestiging. Israel het dus nie dadelik deel gehad in die stedelike kultuur van Palestina nie. „Lank na hierdie vestiging wat nogal vreedsaam geskied het in die dunner bevolkte dele het dit uitgeloop op gewapende botsings. Die Bybelse oorlewering het hierdie krygsoperasies verplaas na die begin van die vestiging en so die volgorde omgekeer.

Naas hierdie topografiese, territoriaal-historiese en vestigings-historiese ondersoekinge van Alt, het hy hom veral onderskei deur sy ondersoek na die geskiedenis van die oud-Israelitiese reg en die konstitusionele geskiedenis van die Israelitiese staatsvorming, soos blyk uit sy „Die Ursprünge des israelitischen Rechts" en "Die Staatenbildung der Israeliten in Palāstina”. Dit het Alt geluk om vormgeskiedenis, argeologie en historiografie tot 'n eenheid saam te voeg. Amerikaanse geleerdes het gespreek van die Leipzig School, waaruit ook Martin Noth voortgekom het. In sy boek geheel in die styl van Alt „Das System der zwölf Stāmme", gaan dit weereens om die vroeë geskiedenis van Israel. Die tradisionele indeling van die Israelitiese volk in twaalf stamme onderwerp Noth aan 'n deeglike ondersoek en kom tot die 
gevolgtrekking dat die twaalfstammeverband 'n voor-staatkundige lewensvorm van Israel bevat, 'n parallel van die Griekse amphiktyonie. Om een sentrale heiligdom $\mathrm{nl}$. die verbondsark het die twaalf stamme vergader, wat saamgesluit het rondom die verering van een God. Die groot werk van Noth „Geschichte Israels", wat geheel in die rigting van Alt beweeg kan tereg beskou word as díe werk van die teenwoordige tyd wat die geskiedenis van Israel betref.

Ons het gesê dat na die eerste wêreldoorlog die opmerksaamheid van die O.T. navorsing toegespits was op die eie aard van die lewe van Israel en daarmee het ook die spesialisasie op die O.T. vakgebied begin. Die probleme van die filologie, argeologie, inleidingswetenskap, eksegese en ook vrae aangaande teologie en geloof het na vore gekom. So het in 1917 die boek van R. Otto "Das Heilige" verskyn, wat 'n groot wending in die godsdienswetenskap veroorsaak het. Otto wys op die geheimenis van die wonder van die ,gans andere", die numen. Op die O.T. wetenskap het die kategorieë van Otto tremendum, fascinans e.s.m. groot invloed gehad. Van ewe groot betekenis as hierdie wending in die godsdiensgeskiedenis was die koms van $\mathrm{K}$. Barth en die sg. dialektiese teologie. So sê hy bv. in 'n beskouing oor Gen. 15 : Ons merk by die aanhoor van hierdie woorde en gebeurtenisse, dat daar iets agter is. In die Bybel is daar 'n nuwe wêreld, die wêreld van God, dáár is nie die dade van mense die hoofsaak nie, maar die doen van God. Vandaar dat Barth dan ook teologiese eksegese wil en omskryf dit as volg: „Ek verstaan daaronder ' $n$ uitleg en verklaring van die Skrifte van die O.T. en N.T. as profeties-apostoliese geskrifte, dus 'n uitleg en 'n verklaring wat die vraag voor oë het, wat aan die apostels en profete te stel is - in hoeverre kry ons hiér in hierdie teks getuienis van die woord van God? Teologiese eksegese is 'n eksegese wat plaasvind onder ' $n$ bepaalde vooronderstelling nl. eerstens, dat die leser dit in gedagte hou dat in hierdie boek die kerk tot dusver die Woord van God gehoor het en tweedens dat die leser of die navorser in hierdie boek lees, met die verwagting dat hy ook self hier vir sy tyd weer die woord van God sal hoor.

Hierdie tendens het die teologiese wetenskap in die algemeen sterk beïnvloed en ook sy spore afgedruk op die studie van die O.T. Daar het 'n teologiese nieubesinning in die O.T. wetenskap ingetree sodat Joh. Hempel in 1927 skrywe - die historieskritiese arbeid in al sy vertakkinge vorm nie ' $n$ teenstelling met die teologiese opvatting van die O.T. as oorkonde van die openbaring nie; dit vorm veelmeer die noodwendige en nie te verwaar- 
loosde vooronderstelling. Wie die oue en die Nuwe Testament wil eksegetiseer kom dus nie sonder vooronderstelling nie. Hy glo dat in die O.T. en N.T. God aan die woord is. Dieselfde geluid verneem ons by Carl Kramer in sy boek „Amos" waar hy sê Die geloof van Amos is geheel en al eskatologies georiënteer; die eskatologie is 'n middel van verkondiging, waardeur aan die volk van Israel, as volk van die verkiesing, elke menslike versekerdheid ontneem word, sodat hy op God alleen gewerp en aangewys is. In dieselfde lyn beweeg ook Eichrodt met sy Theologie des Alten Testaments, waar hy wegbreek van die godsdienshistoriese beskouingswyse en in verset kom teen die alleenheerskappy van die historisme. Die O.T. geloofswêreld moet in sy strukturele samehang met sy religieuse Umwelt en sy wesenssamehang met die N.T. verstaan word. By ons behandeling van die O.T. geloofswêreld, moet ons afsien van die in die christelike dogmatiek gangbare schemata van, Theologie, antropologie en soteriologie en ons liewer orienteer aan die in die O.T. gangbare dialektiek. Eichrodt spreek in sy Theologie dan ook van God en Volk, God en Wêreld en God en Mens. Die verbondsgedagte tree as beheersende idee van die gesamentlike teologiese konsepsie na vore.

Van groot betekenis was die verskyning van die werk van W. Vischer in 1936 „Das Christuszeugnis”. Sy groot verdienste is :

1. Dat dit die O.T. navorsing gewys het op die eenheid van die O.T. en N.T. en op die laaste werklikheid Jesus Christus wat aan die O.T. sin gee.

2. Dit het die wetenskaplike navorsingswerk, wat 'n noukeurige kennis van die ,werklike lewe" van Israel - so Kittel - met die teologiese nuwe besinning verbind, m.a.w. die verbindingslyn tussen die werk van Alt en Pedersen en die Woord van God-teologie van Barth het Vischer duideliker getrek.

Ten slotte wil ons nog enkele gedagtes in u midde lê oor die gang van die eksegetiese arbeid aan die O.T. in die halfeeu wat verby is. In die twintigerjare het die Kommentarereeks K.z.A.T. onder die redaksie van Sellin begin verskyn. Dit het 'n tydlank stilgestaan maar is nou weer in die afgelope jare hervat. In 1935 het gevolg die serie H.A.T. onder leiding van prof. O. Eissfeldt en daarop het gevolg die serie A.T.D. van Herntrich en Weiser. Ons kan dus met vrymoedigheid sê dat in die tyd wat verby is die aandag ook toegespits is op die eksegese. Die reformatoriese besinning na die eerste wêreldoorlog het daartoe gelei dat juis die eksegese opnuut beklemtoon is en opnuut is die vraag gestel 
nl. hoe moet die histories kritiese eksegese met die hermeneutiese riglyn van de reformatoriese Bybeluitleg verbind word. Dit is ' $n$ heersende probleem in die O.T. wetenskap van die huidge tyd. Twee dinge het in elke geval duidelik geword.

1. Die histories-kritiese navorsing het nie konsekwent na die boodskap van die Bybelteks gevra nie maar het hom dikwels laat lei deur 'n rasionalistiese gedagtegang.

2. Dat dit onmoontlik is om reformatoriese Skrifuitleg te bəoefen met verbygaan van die historiese kritiek.

Hierdie twee erkennings het aanleiding gegee tot die teenwoordige hernuwde besinning soos ook blyk uit die versamelwerk uitgegee deur Westermann wat die betekenisvolle titel dra: "Probleme Altestestamenticher Hermeneutik". Uit die debatte rondom die teologiese eksegese het dit duidelik geword dat daar nie soiets as 'n vooronderstellingslose eksegese is nie, dat ook die sg. histories-krities eksegese nie sonder vooronderstellinge is nie en dat alle uitleg van die Skrif, dus ook die O.T. sy doel slegs bereik, wanneer die uitleg ,in Christus" geskied. En by hierdie punt wil ons graag noem die serie kommentare uitgegee deur Martin Noth nl. „Biblischer Kommentar - A.T. „Daarvan skryf Noth by die aanvang van die reeks as volg: Die B.K. sien sy taak só dat dit 'n sorgvuldige, op die Hebreeuse teks van die O.T. gegronde wetenskaplike eksegese wil gee, (dus die historieskritiese nie wil verwaarloos nie) maar dat ook daarin reg sal geskied aan die gegewe dat die N.T. Jesus Christus as die doel van die O.T. Godshandeling verkondig.

Dit laat sien watter nuwe weë teenwoordig in die uitleg van die Ou Testament betree word. Ons eindig daarmee dat in die afgelope halfeeu tot die erkenning gekom is dat die eksegese van die O.T. en N.T. nie doel op homself is nie maar dat dit steeds die verkondiging in die gemeente van Jesus Christus moet dien.

Ek is sterk bewus van die kursoriese en abrupte behandeling van die onderwerp vanaand. Baie wat gesê moes word en kon word moes ek omrede van die tydsfaktor weglaat. $U$ het gemerk dat die Pentateuchvrae, die oor die profete, die oor die inleidingsvraagstuk en tal van ander nie aan die orde gekom het nie; ek was verplig om 'n keuse te maak.

En waar ons nou vanaand terugsien op die vyftig jaar wat verby is, en hierdie jaar die halfeeulange bestaan van die Fakulteit aan die U.P. gedenk, daar is ons dankbaar en bly dat ons 
kerk sy opleiding het, hier in die Noordelike hoofstad van die Republiek. Ons Kerk het altyd sy voorkeur uitgespreek vir universitêre opleiding bo die van 'n kweekskool. Die Kerk het dit so gesien dat sy bedienaars van die Woord universitêrwetenskaplik geskoold moet wees. Dit is nie al nie. By die wetenskaplike vorming moet ons onthou dat ons ook dienare van die Woord binne die Kerk is. Die Kerk het verder bepaal dat die dosente aan die Fakulteit die hoogste akademiese kwalifikasies moet hê. Dit is nie al nie, hulle moet ook dienare van die Woord wees. Hulle is kragtens hulle aanstelling werknemers van die Universiteit, maar vooraf is hulle deur die Kerk toegelaat tot die Evangeliebediening en dit open eers die weg om hoogleraar te kan word en so is dit die beste. Nou kan ek vanaand met die meeste vrymoedigheid hier sê dat al die lede van die Fakulteit in sy teenwoordige samestelling dit so begeer, en wens dat dit nooit anders sal wees of word nie. Mag dit in die nuwe halfeeu of eeue wat voorle ook so bly, dat die professore nooit anders wil wees as dienare van die Woord in die boesem van die Kerk; wel in diens van die teologiese wetenskap, wat immer ' $n$ dienende taak het in die verkondiging in die gemeente van Jesus Christus.

(Rede uitgespreek by die opening van die Kolleges op Maandagaand 13 Februarie in die jubeljaar van die Fakulteit.) 